\title{
Avaliação da percepção de gestantes sobre as doenças cárie e periodontal
}

\author{
Evaluation of pregnant women perception about caries and periodontal diseases \\ Evaluación de la percepción de gestantes sobre la caries \\ $y$ enfermedad periodontal
}

\author{
Marina Tavares Costa NÓBREGA ${ }^{\mathbf{1}}$ \\ Julliana Cariry Palhano FREIRE ${ }^{1}$ \\ Eduardo DIAS-RIBEIRO2 \\ Herbert GHERSEL3 \\ Eloísa Lorenzo de Azevedo GHERSEL ${ }^{3}$
}

\begin{abstract}
${ }^{1}$ Mestranda em Ciências Odontológicas pela Universidade Federal da Paraíba (UFPB), 58051-900 João Pessoa-PB, Brasil ${ }^{2}$ Professor adjunto do Curso de Odontologia da Universidade Federal de Campina Grande (UFCG), 58708-110 Patos-PB, Brasil

${ }^{3}$ Professor (a) adjunto do Curso de Odontologia da Universidade Federal da Paraíba (UFPB), 58051-900 João Pessoa-PB, Brasil
\end{abstract}

\section{Resumo}

Cuidados com saúde bucal e dieta são essenciais, porém, frequentemente negligenciados por gestantes e mães. O presente trabalho tem por objetivo verificar se a população de gestantes atendidas no Hospital Universitário Lauro Wanderley teve acesso a orientações sobre saúde bucal para ela e seu bebê e investigar sua percepção em relação às doenças cárie e periodontal. Foram entrevistadas 30 gestantes atendidas no Hospital Universitário Lauro Wanderley, escolhidas através de amostragem por acessibilidade. Os dados coletados foram tabulados e analisados com a utilização do software SPSS 20.0. A metade das gestantes afirmou ter recebido orientações sobre como cuidar de sua saúde bucal e do futuro bebê. A maioria acredita que a doença cárie é transmissível $(63,0 \%)$ e consideram sua saúde bucal regular (43,0\%), demonstrando que algum nível de informação já fora assimilado. No entanto, apenas $20 \%$ das entrevistadas relatou tratar seus dentes e visitar periodicamente o cirurgião-dentista. A população estudada possui carência de informações sobre saúde bucal e medidas de educação em saúde devem ser instituídas.

Descritores: Saúde Pública; Educação em Saúde Bucal; Gestantes.

\begin{abstract}
Caring for oral health and diet is essential, but often overlooked by pregnant women and mothers. This study aims to determine if the population of pregnant women seen at Lauro Wanderley University Hospital had access to guidelines on oral health for her and her baby and investigate their perception of the caries and periodontal. We interviewed 30 pregnant women in Lauro Wanderley University Hospital chosen through sampling accessibility. Data were tabulated and analyzed using the SPSS 20.0 software. Half of the women said they had received guidance on how to care for your dental health and future baby. Most believe that caries is transmitted (63.0\%) and consider regular their oral health $(43.0 \%)$, demonstrating that some level of information had been assimilated. However, only $20 \%$ of respondents reported treating their teeth and regularly visit the dentist. The study population has a lack of information on oral health and health education measures should be instituted.
\end{abstract}

Descriptors: Public Health; Health Education, Dental; Pregnant Women.

\section{Resumen}

El cuidado de la salud oral y la dieta son esenciales, pero frecuentemente descuidados por las gestantes y madres. Este estudio tiene como objetivo verificar si la población de gestantes atendidas en el Hospital Universitario Lauro Wanderley tuvo acceso a las orientaciones sobre la salud oral de ellas y sus bebés e investigar su percepción en relación a la caries y enfermedad periodontal. Se entrevistaron 30 gestantes en el Hospital Universitario Lauro Wanderley elegidos a través de muestreo por accesibilidad. Los datos fueron tabulados y analizados utilizando el software SPSS 20.0. La mitad de las gestantes afirmaron haber recibido orientación sobre cómo cuidar de su salud bucal y la del futuro bebé. La mayoría cree que la caries es transmisible $(63,0 \%)$ y consideran su salud bucal regular (43,0\%), demostrando que algún nivel de información ya ha sido asimilado. Sin embargo, sólo el $20 \%$ de los entrevistados informó que trataban sus dientes y visitaban al odontólogo regularmente. La población estudiada carece de informaciones sobre salud bucal por lo que medidas de educación en salud deben ser instituidas. Descriptores: Salud Pública; Educación en Salud Dental; Mujeres Embarazadas. 


\section{INTRODUÇÃO}

Cuidados com saúde bucal e dieta são essenciais, porém, frequentemente negligenciados por gestantes e mães ${ }^{1}$. Durante a gestação, a mulher se encontra receptiva à incorporação de novas atitudes e comportamentos $^{2}$. Assim, torna-se importante o papel da gestante e da mãe como agente multiplicador de saúde, visto que a sua percepção sobre saúde bucal influenciará na predisposição para o desenvolvimento da cárie dentária no seu bebể

É importante salientar que a mãe possui um relevante papel dentro do núcleo familiar, um ponto chave na prevenção de doenças quando absorve os conceitos de saúde e introduz bons hábitos na família ${ }^{2,4}$. Portanto, o trabalho educativo com gestantes é a base da promoção da saúde para as gerações que estão por vir ${ }^{5}$.

É neste contexto que o presente trabalho se insere, pois o objetivo é verificar se a população de gestantes envolvidas teve acesso a orientações sobre sua própria saúde bucal e a do bebê, assim como investigar sua percepção em relação às doenças cárie e periodontal.

\section{MATERIAL E MÉTODO}

O projeto foi submetido e aprovado junto ao Comitê de Ética em Pesquisa do Hospital Universitário Lauro Wanderley (HULW), Universidade Federal da Paraíba (UFPB), João Pessoa-PB, Brasil (Parecer n'42030/12).

A população do estudo foi composta por todas as mulheres atendidas no HULW - UFPB, João Pessoa-PB, Brasil, no ambulatório de pré-natal, escolhidas por meio de amostragem por acessibilidade. A amostra foi composta por trinta destas, desde que estivessem no período gestacional.

Foram incluídas no estudo mulheres que estavam no período gestacional, em qualquer fase. Foram excluídas do estudo as mulheres que não sabiam ler/escrever, bem como as que apresentavam alguma deficiência física ou mental, o que as incapacitava a responder ao questionário. Os critérios de exclusão também contemplavam as mulheres que se negaram a assinar o Termo de Consentimento Livre e Esclarecido (TCLE).

Utilizou-se um questionário com perguntas fechadas e abertas direcionado às gestantes, além do TCLE.

Os dados foram tratados estatisticamente utilizando-se o software SPSS versão 20.0. A amostra obtida foi descrita em percentagens e números absolutos, e avaliados por meio de estatística descritiva.

\section{RESULTADOS}

De acordo com a Tabela 1, das 30 gestantes entrevistadas, com idade entre 14 e 41 anos, a maioria afirmou ter recebido orientações sobre as doenças cárie e periodontal, porém $40 \%$ delas não lembram quais informações receberam. Também receberam orientações de como cuidar da própria boca (93\%), mas não sobre a higienização bucal do bebê $(63 \%)$.

Tabela 1. Informações sobre as doenças cárie e periodontal

\begin{tabular}{l|l|l|c}
\hline \multicolumn{1}{c|}{ Questões } & Não & Sim & $\begin{array}{c}\text { Sim, } \\
\text { mas } \\
\text { não } \\
\text { lembro }\end{array}$ \\
\hline $\begin{array}{l}\text { Você já recebeu orientações } \\
\text { sobre as doenças cárie e } \\
\text { inflamação gengival? }\end{array}$ & $20 \%$ & $40 \%$ & $40 \%$ \\
\hline $\begin{array}{l}\text { Você acha que a cárie } \\
\text { dentária pode ser transmitida } \\
\text { por uma bactéria através da } \\
\text { saliva de uma pessoa que tem } \\
\text { cárie para a saliva do bebê? }\end{array}$ & $37 \%$ & $63 \%$ & \\
\hline $\begin{array}{l}\text { Você já recebeu orientações } \\
\text { sobre como cuidar dos seus } \\
\text { dentes e/ou saúde da sua } \\
\text { boca? }\end{array}$ & $7 \%$ & $93 \%$ & \\
\hline $\begin{array}{l}\text { Você já recebeu orientações } \\
\text { sobre como cuidar dos dentes } \\
\text { do futuro bebê? }\end{array}$ & $63 \%$ & $37 \%$ & \\
\hline
\end{tabular}

A situação bucal de $43 \%$ das entrevistadas é considerada por elas mesmas como regular, com presença de lesões de cárie e sangramento gengival ou em tratamento. Entre elas, 53\% afirmam escovar os dentes 3 vezes ao dia, $57 \%$ relatam usar o fio dental, e $63 \%$ informaram procurar tratamento odontológico quando sentem alguma necessidade ou dor. Ao serem indagadas sobre o motivo pelo qual não procuram o tratamento odontológico, algumas mulheres citaram medo, descuido ou falta de tempo como os principais motivos. Apesar da baixa percentagem $(27 \%)$ das que procuram revisões periódicas, a maioria relatou pretender levar o futuro bebê ao dentista mesmo sem a apresentação de algum problema.

Os fatores etiológicos da cárie dentária são desconhecidos para uma parte das entrevistadas, apesar de a maioria ter alguma percepção da etiologia bacteriana e $63 \%$ afirmarem a necessidade de escovação para evitar o problema. Sobre a doença periodontal, impera a desinformação, pois $76 \%$ das gestantes não sabem o que causa. Em relação à etiologia dessa patologia, uma gestante afirmou "[...]Falta de vitaminas e sujeira que provoca cárie e torna sensível a gengiva", enquanto outra respondeu que as lesões de cárie eram as causadoras da inflamação nas gengivas.

Quanto às formas de prevenção da doença periodontal, $74 \%$ das mulheres entrevistadas não souberam responder. E em relação à prevenção contra doença cárie no bebê, $50 \%$ delas não sabem como proceder, porém $20 \%$ citaram a higiene oral como importante fator preventivo. 


\section{DISCUSSÃO}

Verificou-se que $80 \%$ das mulheres da amostra em questão afirmaram ter recebido algum tipo de informação sobre as doenças cárie e periodontal, e um percentual ainda maior das gestantes $(93,3 \%)$ relatou que foram orientadas em relação aos cuidados com a sua própria saúde bucal, corroborando com estudos como o de Vieira e Zocratto ${ }^{6}$ que mostraram que $51,3 \%$ das participantes receberam instruções sobre saúde bucal. Porém na pesquisa de Bastianni et al. ${ }^{7}$ apenas $33 \%$ das mulheres haviam sido previamente esclarecidas sobre como cuidar de seus dentes, assim como relatado por Cruz et al. $^{8}$ que verificaram que $32,5 \%$ das mães entrevistadas receberam informações sobre saúde bucal.

Das gestantes em questão, 50\% não sabiam como evitar a doença cárie em seu bebê, porém outras sabiam que deveriam limpar a boca do bebê com gaze ou pano umedecido, fazer a limpeza dos dentes após as refeições e evitar alimentos que contenham sacarose. Isso demonstra que de alguma forma, já foram orientadas e absorveram conhecimentos relacionados à prevenção. Entre elas, 63,3\% afirmaram não ter recebido nenhum tipo de informação sobre cuidados com a saúde bucal do bebê. Situação semelhante à de Hanna et al. ${ }^{9}$, onde as participantes foram questionadas se já haviam recebido alguma orientação relacionada aos cuidados com higiene bucal em bebês e $48 \%$ afirmaram nunca ter sido orientadas.

A maior parte das gestantes que participaram do presente estudo $(63,3 \%)$ disse que sabia que a doença cárie pode ser transmitida através da saliva, isso também foi constatado na literatura na pesquisa de Moura et al. ${ }^{10}$ e Massoni et al. ${ }^{11}$, onde mais da metade das grávidas afirmou que conhecia esse fato. Apesar de no presente estudo 63,3\% das participantes afirmarem que nunca receberam orientações sobre os cuidados com os dentes do futuro bebê, o mesmo percentual respondeu "sim" quando argumentadas se sabiam que a cárie dentária pode ser transmitida ao bebê através da saliva. Esta resposta pode ser justificada pelo fato delas já terem recebido algumas orientações sobre como cuidar de sua própria saúde bucal, ou por serem induzidas ao "sim", por se tratar de uma questão objetiva.

Nessa pesquisa foi constatado que $63,3 \%$ das grávidas afirmaram que a falta de escovação dentária pode causar lesões de cárie. Significâncias maiores foram encontradas na literatura no estudo de Gunther et al. ${ }^{12}$, onde todas as participantes mencionaram que falta de higiene/não escovação pode causar problemas bucais e uma parte atribuiu este fato à má alimentação ou ao excesso de doce, atribuição esta que também foi citada pelas gestantes participantes do presente estudo.

Entre as práticas adotadas para se evitar a doença cárie, a boa higiene bucal foi citada por $60 \%$ das participantes. No entanto, tratar seus dentes e visitar periodicamente o cirurgião-dentista foram práticas apontadas somente por $20 \%$ das entrevistadas. Estudos como o de Massoni et al. ${ }^{11}$ revelaram que a escovação foi a medida preventiva mais indicada pelas gestantes $(45,6 \%)$, seguida pelo controle no consumo de alimentos doces $(20,5 \%)$.

Dentre as integrantes, a maior parte (76\%) afirmou desconhecer a etiologia da doença periodontal (inflamação gengival), apenas $16,7 \%$ atribuíram os problemas gengivais à deficiência de higiene bucal e $74 \%$ não sabiam como prevenir esse problema ou se abstiveram de resposta. Estes dados contrastam com o estudo de Rios et al. ${ }^{13}$ onde $50 \%$ das gestantes por eles analisadas afirmaram ter conhecimento sobre a gengivite; 55\% não sabiam como evitar; e das $45 \%$ que diziam saber, somente $20 \%$ responderam corretamente: "[...]escovando os dentes".

Dentre as mulheres estudadas, $53,3 \%$ relataram só procurar atendimento odontológico quando alguma coisa incomoda, 36,7\% regularmente para fazer revisão, e $10,0 \%$ só quando sentem dor. As mesmas citaram também fatores como medo, falta de tempo e descuido para não visitarem o cirurgião-dentista, o que foi constatado da mesma forma por Albuquerque et al. ${ }^{14} \mathrm{e}$ Venâncio $^{15}$. No entanto, no estudo de Bastiani et al. ${ }^{7}$ o fator "desnecessário" foi o mais predominante.

Apesar da maioria das futuras mães buscarem atendimento odontológico somente diante de algum fator que justifique, e de muitas delas apresentarem algum tipo de doença bucal, 6,7\% manifestaram a intenção de levar a criança à primeira consulta apenas quando houver algum problema odontológico e grande parte delas tem a intenção de levar antes disso. $O$ momento ideal considerado por $53,3 \%$ das grávidas para a primeira visita do bebê ao consultório odontológico foi quando estiverem nascendo os primeiros dentinhos. Outros autores como Massoni et al. ${ }^{11}$ relataram que 36,2\% das gestantes acreditam que o melhor momento para a primeira visita da criança ao cirurgião-dentista é quando todos os dentes estiverem presentes na cavidade bucal, e Gunther et al. ${ }^{12}$ e Hanna et al. ${ }^{9}$ verificaram que a maior parte das participantes acha ser o momento ideal antes do primeiro ano de vida.

$\mathrm{Na}$ presente pesquisa, $43,3 \%$ das gestantes consideraram a saúde da sua boca regular e 36,7\% considerou boa. Assim como o estudo de Venâncio ${ }^{15}$ que observou que a maioria da sua amostra avaliou a própria condição bucal como regular $(37,7 \%)$ e boa $(39,6 \%)$. No presente estudo, 50,0\% das gestantes afirmaram escovar os dentes três vezes ao dia, corroborando com os resultados de Moura et al. ${ }^{10} \mathrm{e}$ Martins et al. ${ }^{16}$. Quanto ao uso do fio dental, $56,7 \%$ das gestantes relataram seu uso, valor próximo aos encontrados em outros estudos, que foram $68,75 \%$ no estudo de Rios et al. ${ }^{13}$ e $62,7 \%$ na 
pesquisa de Venâncio ${ }^{15}$. Porém, Moimaz et al. ${ }^{17}$ (2011) encontraram porcentagens de gestantes que afirmam não usar o fio dental de $60 \%$ e Moura et al. ${ }^{10}$ de $64 \%$.

\section{CONCLUSÃO}

Grande número de gestantes teve acesso a informações sobre cuidados com sua saúde bucal, porém demonstraram falta de conhecimento em relação aos cuidados do bebê. As entrevistadas conheciam a etiologia e prevenção da doença cárie, porém isso não ocorreu sobre a doença periodontal. A população estudada possui carência de informações sobre saúde bucal e medidas de educação em saúde devem ser instituídas.

\section{REFERÊNCIAS}

1. Fitzsimons D, Dwyer JT, Palmer C, Boyd LD. Nutrition and oral health guidelines for pregnant women, infants, and children. J Am Diet Assoc 1998; 98(2):182-9.

2. Costa ICC, Marcelino G, Berti, GM, Saliba NA. A gestante como agente multiplicador de saúde. RPG Rev Pos-Grad. 1998;5(2):87-92.

3. Vorkuka VL, Eduardo MAP, Carcacés LB, Valdés GO, Walter LRF. Odontologia intrauterina: o começo de tudo. Rev ABO Nac. 1997; 5(2):70-7.

4. Peres SHCS, Cardoso MTV, Garcez RMVB, Peres AS, Bastos JRM. Tratamento alternativo de controle da cárie dentária no período materno-infantil. Rev APCD. 2001;55(5):346-51.

5. Zardetto CGDC, Rodrigues CRMD, Ando T. Avaliação dos conhecimentos de alguns tópicos de saúde bucal de gestantes de níveis sócio-culturais diferentes. RPG Rev Pos-Grad. 1998; 5(1):69-74.

6. Vieira GF, Zocratto KBF. Percepção das gestantes quanto a sua saúde bucal. RFO. 2007;12(2):27-31.

7. Bastiani C, Cota ALS, Provenzano MGA, Fracasso MLC, Honório HM, Rios D. Conhecimento das gestantes sobre alterações bucais e tratamento odontológico durante a gravidez. Odontol Clín-Cient. 2010; 9(2):155-60.

8. Cruz AAG, Gadelha CGF, Cavalcanti AL, Medeiros PFV. Percepção materna sobre a higiene bucal em bebês: Um estudo no hospital Alcides Carneiro, Campina Grande - PB. Pesq Bras Odontopediatr Clín Integr. 2004; 4(2):185-9.

9. Hanna LMO, Nogueira AJS, Honda VYS. Percepção das gestantes sobre atenção odontológica precoce nos bebês. RGO. 2007;55(3):271-4.

10. Moura CO, Aleixo RQ, Almeida FA, Silva HML, Moreira KFA. Prevalência de cárie em adolescentes gestantes relacionada ao conhecimento sobre saúde bucal em Porto Velho - RO. Saber Cient Odontol. 2010;1(1):1-20.

11. Massoni ACLT, Ferreira JMS, Silva FDSCM, Carvalho LFPC, Duarte RC. Conhecimento de gestantes sobre a saúde bucal dos bebês. Rev bras ci Saúde. 2009; 13(1):41-7.

12. Günther K, Tovo MF, Feldens CA. Avaliação dos conhecimentos sobre saúde bucal referidos por parturientes do hospital luterano - ULBRA. Stomatos. 2005;11(20):5-12.

13. Rios D, Bastiani C, Provenzano MGA, Fracasso MLC. Relato de gestantes quanto a ocorrência de alterações bucais e mudanças nos hábitos de dieta e higiene bucal. Iniciação Científica CESUMAR. 2007;09:63-8.

14. Albuquerque OMR, Abegg C, Rodrigues CS. Percepção de gestantes do Programa Saúde da Família em relação a barreiras no atendimento odontológico em Pernambuco, Brasil. Cad Saúde Pública. 2004; 20(3):789-96.

15. Venâncio EQ. Avaliação dos conhecimentos e práticas de saúde bucal de gestantes, usuárias do SUS, no município de Dourados - Mato Grosso do Sul. [dissertação]. Brasília: Universidade de Brasília; 2006.

16. Martins RFO, Martins ZIO. O que as gestantes sabem sobre cárie: Uma avaliação dos conhecimentos de primigestas e multigestas quanto à própria saúde bucal. Rev ABO Nac. 2002; 10(5):278-84.

17. Moimaz, SAS, Garbin CAS, Rocha NB, Santos SMG, Saliba NA. Resultados de dez anos do Programa de Atenção Odontológica à Gestante. Rev Ciênc Ext. 2011;7(1):42-56.

\section{CONFLITO DE INTERESSES}

Os autores declaram não haver conflitos de interesse.

\section{AUTOR PARA CORRESPONDÊNCIA}

Marina Tavares Costa Nóbrega

marinatcn@hotmail.com
Submetido em 14/08/2016 Aceito em 19/09/2016 